\title{
THÓI QUEN TìM KIÉM THÔNG TIN COVID - 19 QUA INTERNET CỦA SINH VIÊN NĂM THỨ' NHẤT TRƯỜNG ĐẠI HỌC Y HÀ NỌI
}

\author{
Đào Văn Phương, Phạm Thị Diệu Linh, Trần Linh Thảo, Nguyễn Duy Phước, \\ Đặng Công Sơn, Đặng Thu Trang, Nguyễn Thị Hương Thảo, Đoàn Thu Huyên, \\ Phan Thanh Hải, Lê Xuân Hưng và Lê Thị Thảo Linh $\bowtie$
}

Trường Đại học Y Hà Nội

Nghiên cứu mô tả cắt ngang được thực hiện trên sinh viên năm thứ nhất Trường Đại học Y Hà Nội nhằm mô tả thói quen tìm kiếm thông tin COVID - 19 qua Internet và phân tích sự khác biệt về điểm eHEALS (thang đo khả năng đọc viết eHealth (eHealth Literacy Scale)) giữa các nhóm đối tượng. Trong 346 người tham gia, có tới $94,8 \%$ sử dụng Internet để tìm kiếm thông tin sức khỏe về COVID - 19. Trong đó, tổng điểm eHEALS đạt mức cao (31,19 ะ 8,34); điện thoại thông minh được đa số người sử dụng (96,65\%); đối tượng chủ yếu tìm kiếm cho bản thân (77,46\%); phổ biến nhất với tần suất 3 lần/tháng hoặc ít hơn (54,27\%). Nội dung sức khỏe được tìm kiếm phổ biến nhất là tình hình dịch bệnh ở Việt Nam và trên thế giới $(88,72 \%)$ với lý do chủ yếu là mong muốn nâng cao kiến thức hoặc tò mò (75,61\%). Mạng xã hội là nguồn thông tin phổ biến nhất đối với những người tham gia nghiên cứu (69,21\%) với lý do được đưa ra chủ yếu là đặc tính dễ theo dõi/sử dụng (53,66\%). Có sự khác biệt có ý nghĩa thống kê về điểm eHEALS giữa 2 nhóm tần suất tìm kiếm trực tuyến thông tin COVID - $19(p<0,05)$.

Từ khóa: tìm kiếm thông tin, thông tin sức khỏe, Internet, COVID - 19, eHEALS, sinh viên Y.

\section{I. ĐĂT VẤN ĐÊ}

Trước sự lây lan rộng rãi và nguy hiểm của virus SARS - CoV - 2, chủng virus mới gây nên bệnh suy hô hấp cấp nghiêm trọng (COVID 19), ${ }^{1}$ một số nước, bao gồm Việt Nam đã thực hiện biện pháp giãn cách xã hội. Việc áp dụng giãn cách xã hội và khuyến khích người dân học tập và làm việc tại nhà đã ảnh hưởng đến xã hội, kinh tế, du lịch, giáo dục...² Với tình hình hoạt động gặp mặt trực tiếp bị hạn chế, các phương thức giao lưu qua Internet được ưu tiên và ngày càng thông dụng. Các tin tức trực tuyến vì vậy trở nên phổ biến hơn do nhu cầu tìm kiếm thông tin y tế, sức khỏe về loại virus mới của người dùng trên toàn thế giới tăng cao. ${ }^{3}$ Mặc dù Internet là một nguồn thông

Tác giả liên hệ: Lê Thị Thảo Linh

Trường Đại học Y Hà Nội

Email: thaolinh1518@gmail.com

Ngày nhận: 11/08/2021

Ngày được chấp nhận: 06/09/2021 tin y tế dồi dào và cập nhật hàng ngày, tuy vậy vẫn luôn tiềm ẩn nhiều tin tức giả mạo, gây ảnh hưởng xấu đến xã hội và đe dọa sức khỏe cộng đồng. Do vậy, người dân cần thận trọng trong việc tìm kiếm và cập nhật thông tin chính thống về dịch bệnh COVID - 19. ${ }^{4}$ Với số lượng người sử dụng Internet tại Việt Nam tăng cao trong những năm gần đây, ${ }^{5}$ hành vi lan truyền thông tin giả mạo, sai sự thật trong tình hình dịch COVID - 19 vẫn tiếp tục diễn ra, ${ }^{6}$ dù chính phủ Việt Nam đã ban hành luật lệ để răn đe tình trạng này. ${ }^{7}$

Các nhân viên y tế (NVYT), bao gồm sinh viên $Y$, có vai trò quan trọng trong khám chữa bệnh và cung cấp những thông tin y tế đúng đắn, do đó hành vi tìm kiếm thông tin sức khỏe của những đối tượng này càng cần được quan tâm hơn. Hơn nữa, đối tượng sinh viên Y năm thứ nhất mới tiếp xúc với kiến thức $y$ học chuyên sâu, dễ bị ảnh hưởng sai lệch trong 
hành vi nếu không có nhận thức đúng đắn. Vì vậy, nghiên cứu "Thói quen tìm kiếm thông tin sức khỏe về COVID - 19 qua Internet của sinh viên năm thứ nhất Trường Đại học $\mathrm{Y}$ Hà Nội" được tiến hành nhằm mô tả thói quen tìm kiếm thông tin COVID - 19 qua Internet và phân tích sự khác biệt về điểm eHEALS giữa các nhóm đối tượng sinh viên năm thứ nhất trường Đại học $Y$ Hà Nội.

\section{II. ĐÓI TƯỢNG VÀ PHƯƠNG PHÁP}

\section{1. Đối tượng}

Đối tượng đích của nghiên cứu là sinh viên năm thứ nhất trường Đại học $\mathrm{Y}$ Hà Nội.

\section{Tiêu chuẩn lựa chọn}

- sinh viên năm thứ nhất đang học tập tại Trường Đại học $Y$ Hà Nội.

- Có sử dụng mạng Internet, có quyền truy cập vào bộ câu hỏi khảo sát trực tuyến.

- Tự nguyện tham gia nghiên cứu.

\section{Tiêu chuẩn loại trù̀}

Bản ghi trùng địa chỉ e - mail/số điện thoại.

\section{Thời gian và địa điểm nghiên cứu}

Thời gian nghiên cứu từ tháng 12/2020 đến tháng 5/2021.

Nghiên cứu này được thực hiện ở Trường Đại học Y Hà Nội, số 1 phố Tôn Thất Tùng, phường Trung Tự, quận Đống Đa, Hà Nội.

\section{Thiết kế nghiên cứu}

Nghiên cứu mô tả cắt ngang.

\section{Phương pháp}

\section{Cõ̃ mẫu}

Áp dụng công thức ước tính cỡ mẫu cho một tỷ lệ trong quần thể:

$$
n=Z_{\left(1-\frac{\alpha}{2}\right)}^{2} \cdot \frac{p(1-p)}{(p . \varepsilon)^{2}}
$$

Trong đó:

$\mathrm{n}$ là cỡ mẫu tối thiểu cần thiết

$\alpha$ là mức ý nghĩa thống kê. Chọn $\alpha=0,05$ tương ứng với độ tin cậy $95 \% . Z_{(1-a / 2)}=1,96$. $p=0,78$ (tỷ lệ sinh viên năm thứ nhất trong một khóa học bắt buộc tại một trường đại học công lập miền Trung Tây được báo cáo là tìm kiếm thông tin sức khỏe trực tuyến ${ }^{8}$ and $82 \%$ ( $n=1,060)$

$\varepsilon$ là độ lệch tương đối giữa tham số mẫu và tham số tổng thể. Trong nghiên cứu này chấp nhận $\varepsilon=0,06$

Sau khi tính toán, cỡ mẫu tối thiểu được tính là 301. Trên thực tế, chúng tôi đã khảo sát trên 346 đối tượng.

\section{Cách chọn mẫu}

Phương pháp chọn mẫu thuận tiện.

\section{Công cụ và phương pháp thu thập}

Câu hỏi được sử dụng trong nghiên cứu này đã được điều chỉnh dựa trên bộ câu hỏi gốc của hai tác giả David Ka - Ki Wong and Man - Kuen Cheung: "Online Health Information Seeking and eHealth Literacy Among Patients Attending a Primary Care Clinic in Hong Kong: A Cross Sectional Survey". ${ }^{9}$

Nghiên cứu này sử dụng phương pháp thu thập số liệu trực tuyến qua Google Forms bằng bộ câu hỏi khảo sát trực tuyến gồm 4 phần:

Phần 1 là thông tin chung bao gồm các chỉ số về tuổi, giới, dân tộc, tôn giáo, ngành học.

Phần 2 bao gồm các thói quen về kết nối và sử dụng Internet như thiết bị sử dụng, thời gian, mức độ sử dụng Internet.

Phần 3 tìm hiểu về thói quen tìm kiếm trực tuyến thông tin COVID - 19 với các chỉ số như thiết bị, mức độ tìm kiếm, nội dung và lý do tìm kiếm, nguồn tìm kiếm và lý do chọn nguồn.

Phần 4 biểu diễn thang đo eHEALS (eHealth Literacy Scale), là một thước đo gồm 8 mục dùng để đo lường khả năng đọc viết của eHealth theo thang Likert 5 điểm (1 = rất không đồng ý, 5 = rất đồng ý), với tổng điểm nằm trong khoảng 8 - 40, điểm cao hơn cho thấy khả năng đọc viết cao hơn. Thang đo này được thiết kế để đo lường kiến thức, kỹ năng nhận thức trong 
việc tìm kiếm, đánh giá và áp dụng thông tin sức khỏe điện tử cho các vấn đề sức khỏe của người tham gia ${ }^{10}$

\section{Xử lý số liệu}

Số liệu được quản lý, làm sạch và phân tích bằng phần mềm STATA 16.0.

Các thống kê mô tả sẽ được thực hiện thông qua việc tính toán giá trị trung bình, độ lệch chuẩn cho các biến định lượng và tỷ số, tỷ lệ cho các biến định tính.

Thống kê suy luận: sử dụng Mann - Whitney test kiểm định sự khác biệt giữa 2 nhóm độc lập.

\section{4. Đạo đức nghiên cứu}

Người tham gia nghiên cứu hiểu rõ mục đích và ý nghĩa của nghiên cứu, từ đó có sự đồng thuận khi tham gia. Các thông tin của đối tượng nghiên cứu chỉ phục vụ cho mục đích nghiên cứu và được đảm bảo giữ bí mật.

\section{KÉT QUẢ}

Bảng 1. Thông tin chung của đối tượng nghiên cứu ( $\mathrm{N}=346)$

\begin{tabular}{|c|c|c|}
\hline \multicolumn{2}{|c|}{ Đặc điểm chung của đối tượng } & \multirow{2}{*}{$\begin{array}{c}\text { Mean } \pm \text { SD hoặc } \mathbf{n}(\%) \\
19,29 \pm 1,24\end{array}$} \\
\hline Tuổi & & \\
\hline \multirow{2}{*}{ Giới tính } & Nư & $244(70,52)$ \\
\hline & Nam & $102(29,48)$ \\
\hline \multirow{2}{*}{ Dân tộc } & Kinh & $307(88,73)$ \\
\hline & Thiểu số & $39(11,27)$ \\
\hline \multirow{2}{*}{ Tôn giáo } & Không & $330(95,38)$ \\
\hline & Có & $16(4,62)$ \\
\hline \multirow{10}{*}{ Ngành học } & BS Y khoa & $118(34,10)$ \\
\hline & CN Điều dưỡng & $63(18,21)$ \\
\hline & BS Y học dự phòng & $42(12,14)$ \\
\hline & CN Y tế công cộng & $26(7,51)$ \\
\hline & CN Khúc xạ nhãn khoa & $24(6,94)$ \\
\hline & CN Dinh dưỡng & $24(6,94)$ \\
\hline & BS Răng - hàm - mặt & $19(5,49)$ \\
\hline & CN Kỹ thuật Xét nghiệm y học & $13(3,76)$ \\
\hline & CN Điều dưỡng tiên tiến & $9(2,60)$ \\
\hline & BS Y học cổ truyền & $8(2,31)$ \\
\hline
\end{tabular}

Bảng 1 trình bày đặc điểm chung của 346 đối tượng tham gia nghiên cứu. Mẫu nghiên cứu có tuổi trung bình là $19,29 \pm 1,24$, nư giới chiếm tỷ lệ khá cao $(70,52 \%)$ so với nam giới $(29,48 \%)$. Phần lớn người tham gia là dân tộc Kinh $(88,73 \%)$ và không có tôn giáo $(95,38 \%)$. Trong số 10 ngành học, đối tượng bác sĩ Y khoa chiếm tỷ lệ lớn nhất với 34,10\%. 
Bảng 2. Thói quen sử dụng Internet của đối tượng nghiên cứu ( $\mathrm{N}=346)$

\begin{tabular}{|c|c|c|}
\hline \multicolumn{2}{|l|}{ Đặc điểm } & n (\%) hoặc Mean \pm SD \\
\hline \multirow{4}{*}{ Thiết bị kết nối Internet* } & Điện thoại thông minh & $332(95,95)$ \\
\hline & Máy tính xách tay & $187(54,05)$ \\
\hline & Máy tính để bàn & $26(7,51)$ \\
\hline & Máy tính bảng & $17(4,91)$ \\
\hline \multirow{2}{*}{ Mức độ thường xuyên sử dụng Internet } & Vài lần/ngày & $329(95,09)$ \\
\hline & 1 lần/ngày hoặc ít hơn & $17(4,91)$ \\
\hline \multirow{2}{*}{$\begin{array}{l}\text { Số giờ sử dụng Internet trung bình } \\
\text { trong một ngày }\end{array}$} & Từ 3 giờ trở lên & $229(66,18)$ \\
\hline & Dưới 3 giờ & $117(33,82)$ \\
\hline \multirow{2}{*}{$\begin{array}{l}\text { Tìm kiếm trực tuyến thông tin sức khỏe } \\
\text { về COVID - } 19\end{array}$} & Có & $328(94,80)$ \\
\hline & Không & $18(5,20)$ \\
\hline Tổng điểm eHEALS & & $31,19 \pm 8,34$ \\
\hline *Câu hỏi nhiều lựa chọn & & \\
\hline
\end{tabular}

Bảng 2 thể hiện thói quen sử dụng Internet của đối tượng nghiên cứu. Trong 346 người tham gia, 95,95\% sinh viên năm thứ nhất sử dụng điện thoại thông minh để kết nối Internet, thể hiện sự ưu tiên về độ tiện lợi, cập nhật thông tin nhanh chóng. Phần lớn đối tượng thường xuyên sử dụng Internet với mức độ vài lần/ngày $(95,09 \%)$ và từ 3 giờ trở lên trong một ngày $(66,18 \%)$. Hầu hết đối tượng $(94,80 \%)$ sử dụng Internet để tìm kiếm thông tin sức khỏe về COVID - 19. Tổng điểm eHEALS trung bình của người tham gia là $31,19 \pm 8,34$ (phụ lục 1,2).

Bảng 3. Thói quen tìm kiếm trực tuyến thông tin sức khỏe về COVID - 19 của đối tượng nghiên cứu ( $\mathrm{N}=328)$

\section{Câu hỏi}

Tần suất tìm kiếm trực tuyến thông tin COVID - 19

Thiết bị tìm kiếm*

(2)

Trả lò̀i

\begin{tabular}{lc}
\hline lần/tháng trở xuống & $178(54,27)$ \\
\hline 4 lần/tháng trở lên & $150(45,73)$ \\
\hline Điện thoại thông minh & $317(96,65)$ \\
\hline Máy tính xách tay & $137(41,77)$ \\
\hline Máy tính để bàn & $20(6,10)$ \\
\hline Máy tính bảng & $13(3,96)$ \\
\hline Bản thân & $268(77,46)$ \\
\hline Gia đình, người thân & $255(73,70)$ \\
\hline Bạn bè & $141(40,75)$ \\
\hline
\end{tabular}

$$
\text { n (\%) }
$$
$178(54,27)$ $150(45,73)$ 


\begin{tabular}{|c|c|c|}
\hline Câu hỏi & Trả lò̀i & n (\%) \\
\hline \multirow{4}{*}{ Nội dung tìm kiếm } & Tình hình dịch bệnh ở Việt Nam và trên thế giới & $291(88,72)$ \\
\hline & Triệu chứng & $268(81,71)$ \\
\hline & $\begin{array}{l}\text { Biện pháp phòng ngừa (khẩu trang, nước sát } \\
\text { khuẩn, cách ly, ...) }\end{array}$ & $241(73,48)$ \\
\hline & Thuốc điều trị/vắc - xin & $171(52,13)$ \\
\hline \multirow{3}{*}{ Lý do tìm kiếm* } & Nâng cao kiến thức hoặc tò mò & $248(75,61)$ \\
\hline & $\begin{array}{l}\text { Nghe hoặc nhìn thấy một số thông tin, tin tức } \\
\text { mới về COVID - } 19 \text { trên các phương tiện thông } \\
\text { tin đại chúng mà bạn muốn tìm hiểu }\end{array}$ & $240(73,17)$ \\
\hline & $\begin{array}{l}\text { Quyết định thay đổi thói quen hành vi hàng } \\
\text { ngày để phòng ngừa COVID - } 19 \text { (đeo khẩu } \\
\text { trang, rửa tay thường xuyên, cách ly xã hội, ...) }\end{array}$ & $190(57,93)$ \\
\hline \multirow{4}{*}{ Nguồn thông tin* } & Mạng xã hội (Facebook, Twitter, ...) & $227(69,21)$ \\
\hline & $\begin{array}{l}\text { Trang tin tức (Sức khỏe \& Đời sống, } \\
\text { Vietnamnet, Dân trí, ...) }\end{array}$ & $214(65,24)$ \\
\hline & Chính phủ & $190(57,93)$ \\
\hline & Các Trường Đại học Y & $170(51,83)$ \\
\hline \multirow{3}{*}{ Lý do chọn nguồn thông tin* } & Dễ theo dõi/sử dụng & $176(53,66)$ \\
\hline & $\begin{array}{l}\text { Xu hướng hàng đầu trên thanh công cụ tìm } \\
\text { kiếm }\end{array}$ & $175(53,35)$ \\
\hline & Dễ hiểu & $171(52,13)$ \\
\hline
\end{tabular}

*Câu hỏi nhiều lựa chọn

Bảng 3 cho biết thói quen tìm kiếm trực tuyến thông tin COVID - 19 của 328 đối tượng. Hơn nửa $(54,27 \%)$ sinh viên năm thứ nhất tìm kiếm trực tuyến thông tin COVID - 19 với tần suất 3 lần/ tháng hoặc ít hơn. Hầu hết đối tượng sử dụng điện thoại thông minh (96,65\%). sinh viên thường tìm kiếm các thông tin sức khỏe cho bản thân và gia đình với trên $70 \%$ người tham gia chọn hai phương án này. Nội dung mà người tham gia tìm kiếm nhiều nhất là tình hình dịch bệnh ở Việt Nam và trên thế giới $(88,72 \%)$. Lý do phổ biến nhất là mong muốn nâng cao kiến thức hoặc tò mò $(75,61 \%)$. Đối tượng nghiên cứu tìm kiếm ở các nguồn thông tin phổ biến nhất là mạng xã hội $(69,21 \%)$. Hơn một nửa số người tham gia tìm kiếm từ nguồn thông tin đó vì dễ theo dõi/sử dụng $(53,66 \%)$, các thông tin đó là xu hướng hàng đầu trên thanh công cụ tìm kiếm $(53,35 \%)$ và dễ hiểu $(52,13 \%)$. 
Bảng 4. Điểm eHEALS của đối tượng theo đặc điểm nhân khẩu học và thói quen tìm kiếm trực tuyến thông tin của đối tượng nghiên cứu ( $\mathrm{N}=328)$

\begin{tabular}{|c|c|c|c|}
\hline \multicolumn{2}{|c|}{ Đặc điểm } & p50 (p25; p75) & p \\
\hline \multirow{2}{*}{ Giới tính } & Nữ & $33(27 ; 40)$ & \multirow{2}{*}{0,9110} \\
\hline & Nam & $34(25 ; 40)$ & \\
\hline \multirow{2}{*}{ Dân tộc } & Kinh & $33(25 ; 39)$ & \multirow{2}{*}{0,4315} \\
\hline & Thiểu số & $34(28 ; 40)$ & \\
\hline \multirow{2}{*}{ Tôn giáo } & Không & $33(25 ; 40)$ & \multirow{2}{*}{0,6194} \\
\hline & Có & $34(31 ; 37)$ & \\
\hline \multirow{2}{*}{ Hệ đào tạo } & Bác sỹ & $34(25 ; 40)$ & \multirow{2}{*}{0,3477} \\
\hline & Cử nhân & $32(26 ; 37)$ & \\
\hline \multirow{2}{*}{$\begin{array}{l}\text { Mức độ thường xuyên sử dụng } \\
\text { Internet }\end{array}$} & Vài lần/ngày & $33(27 ; 40)$ & \multirow{2}{*}{0,5047} \\
\hline & 1 lần/ngày hoặc ít hơn & $31(21 ; 40)$ & \\
\hline \multirow{2}{*}{ Thời gian sử dụng Internet 1 ngày } & Từ 3 giờ trở lên & $34(25 ; 40)$ & \multirow{2}{*}{0,4399} \\
\hline & $<3$ giờ & $32(26 ; 37)$ & \\
\hline \multirow{2}{*}{$\begin{array}{l}\text { Mức độ sử dụng Internet để tìm kiếm } \\
\text { thông tin COVID - } 19\end{array}$} & $\begin{array}{l}4 \text { lần/tháng hoặc nhiều } \\
\text { hơn }\end{array}$ & $34(28 ; 39)$ & \multirow[t]{2}{*}{$0,0307^{*}$} \\
\hline & 3 lần/tháng hoặc ít hơn & $31(24 ; 40)$ & \\
\hline
\end{tabular}

${ }^{*} p<0,05$ (Mann - Whitney test)

Sự khác biệt của điểm eHEALS giữa các nhóm đặc điểm của đối tượng nghiên cứu được thể hiện trong Bảng 4. Trong số các đặc điểm về nhân khẩu học và thói quen tìm kiếm trực tuyến thông tin COVID - 19, duy nhất sự khác biệt về điểm eHEALS giữa 2 nhóm mức độ tìm kiếm thông tin trực tuyến COVID - 19 là có ý nghĩa thống kê $(p<0,05)$. Ngoài ra, không có sự khác biệt điểm eHEALS giữa các nhóm: giới tính, dân tộc, tôn giáo, hệ đào tạo, thu nhập trung bình, mức độ thường xuyên sử dụng Internet, số giờ sử dụng Internet trong 1 ngày.

\section{BÀN LUẬN}

Nghiên cứu được tiến hành trên đối tượng nghiên cứu có đặc điểm chung là các sinh viên năm thứ nhất Đại học $Y$ Hà Nội với tuổi trung bình là 19,29 $\pm 1,24$ và số lượng sinh viên nữ gấp 3 lần số lượng sinh viên nam. Hầu hết đối tượng là người dân tộc Kinh và không theo tôn giáo. Phần lớn sinh viên học ngành $B S$ đa khoa.

Mức độ thường xuyên sử dụng Internet của sinh viên $Y$ trong nghiên cứu này ở mức cao, tương đồng với kết quả nghiên cứu trên sinh viên điều dưỡng ở Nepal năm 2019.11 Tuy nhiên, tần suất sử dụng Internet để tìm kiếm thông tin về COVID - 19 thấp hơn kết quả của nghiên cứu vừa đề cập, đa số chỉ 3 lần/tháng hoặc ít hơn. ${ }^{11}$ Dẫu vậy, tỷ lệ số sinh viên sử dụng Internet tìm kiếm thông tin sức 
khỏe về COVID - 19 trong nghiên cứu này vẫn cao $(94,80 \%)$, cao hơn tỷ lệ của sinh viên năm thứ nhất trong một khóa học bắt buộc tại một trường đại học công lập miền Trung Tây trước khi dịch COVID - 19 diễn ra. ${ }^{8}$ Bối cảnh dịch COVID - 19 đã thúc đẩy đối tượng tìm kiếm trực tuyến thông tin sức khỏe, tuy nhiên hành vi này chưa phải thói quen có tính thường xuyên mà chủ yếu để thỏa mãn sự tò mò và nhu cầu tìm kiếm thông tin nhất thời.

Mức độ hiểu biết về eHealth của đối tượng nghiên cứu của chúng tôi cao đáng kể so với các báo cáo khác ở trong và ngoài nước. Cụ thể hơn, tổng điểm eHEALS trong nghiên cứu này $(31,19 \pm 8,34)$ được ghi nhận là cao hơn so với điểm eHEALS của đối tượng sinh viên $Y$ năm thứ năm tại một trường đại học $Y$ ở miền trung Việt Nam $(27,03 \pm 3,54)^{12}$, và sinh viên Y khoa và Khoa học sức khỏe ở Iran (28,21 I $6,95)^{13}$. Sự khác biệt này được giải thích bởi mức độ tự tin về kỹ năng tìm kiếm thông tin sức khỏe của đối tượng cao. Mặt khác, sinh viên $Y$ có nhu cầu và mối quan tâm lớn đến tình hình dịch bệnh do đặc thù ngành học liên quan đến sức khỏe con người. Điều này cũng được giải thích trong kết quả của chúng tôi khi lý do tìm kiếm thông tin phổ biến nhất của các đối tượng là nâng cao kiến thức hoặc tò mò. Hơn nữa, nghiên cứu này được thực hiện trong bối cảnh dịch COVID - 19, vì đối tượng là sinh viên $Y$ của một trong nhưng trường đại học hàng đầu đào tạo về nhân lực y tế của Việt Nam, nên càng cẩn trọng hơn trong việc tìm kiếm thông tin sức khỏe liên quan, tư đó mức độ hiểu biết eHealth cũng cao tương ứng.

Nguồn thông tin trực tuyến được sử dụng nhiều nhất là các trang mạng xã hội. Kết quả này tương đồng với một nghiên cứu trên thanh niên Việt Nam, trong đó cho thấy phần lớn người tham gia quan tâm đến thông tin sức khỏe trên Facebook và tin rằng các thông tin tương ứng là đáng tin cậy và hữu ích mặc dù các trang mạng xã hội vẫn luôn tiềm ẩn nhiều thông tin sai lệch tràn lan. ${ }^{14}$ Về mặt tích cực, nhận thấy sự phổ biến của các trang mạng xã hội, Chính phủ và Bộ $Y$ tế, cũng như các cơ quan, tổ chức đã tích cực, tăng cường truyền thông thông tin trên các trang Facebook, tài khoản Tik Tok, video Youtube... bên cạnh website chính thức và các phương tiện truyền thống khác, nhằm tiếp cận đến nhiều đối tượng hơn và nâng cao hiệu quả truyền thông các thông tin y tế trong mùa dịch COVID - 19;15 do vậy, đây có thể là lý do sinh viên chủ yếu tìm hiểu tin tức sức khỏe từ nguồn thông tin trên các mạng xã hội.

Nghiên cứu của chúng tôi chỉ nhận thấy có sự khác biệt giữa điểm eHEALS của nhóm tìm kiếm thông tin sức khỏe ít nhất 1 lần/tuần và nhóm ít hơn vài lần/tháng $(p<0,05)$. Nghiên cứu ở 152 sinh viên điều dưỡng ở Nepal cũng chỉ ra rằng có khác biệt có ý nghĩa thống kê giữa các mức độ tìm kiếm thông tin. ${ }^{11}$ Trong khi đó, nghiên cứu ở Trường Đại học $\mathrm{Y}$ của Mashhad, Iran chỉ ra có sự khác biệt đáng kể về điểm eHEALS giữa các giới tính $(p<$ $0,001)$, thu nhập hàng tháng $(p=0,03)$. Hai tác giả Nguyễn Hoàng Lan và Lê Thị Bích Thủy chỉ ra có sự khác biệt giữa điểm eHEALS của sinh viên nam và nữ trong nghiên cứu ở Đại học $Y$ Dược Huế. ${ }^{12}$ Nghiên cứu của chúng tôi không có những sự khác biệt đó có thể là do sự tương đồng về các đặc điểm nhân khẩu học như tuổi, giới tính, dân tộc, tôn giáo. Sự phân bố về tỷ lệ giữa các nhóm trong đặc điểm nhân khẩu học không đồng đều, nên sự khác biệt về điểm eHEALS của các nhóm này là không đáng kể.

\section{KÉT LUẦN}

Tổng điểm trung bình eHEALS của sinh viên năm thứ nhất trường Đại học $\mathrm{Y}$ Hà Nội ở mức cao. Hầu hết đối tượng có thói quen tìm kiếm 
trực tuyến thông tin sức khỏe liên quan đến COVID - 19. Trong đó, tình hình dịch bệnh ở Việt Nam và trên thế giới được tìm kiếm nhiều nhất, chủ yếu vì mong muốn nâng cao kiến thức hay tò mò; mạng xã hội là nguồn thông tin được nhiều người tìm kiếm nhất vì họ cho rằng những nguồn này dễ theo dõi/sử dụng. Có sự khác biệt có ý nghĩa thống kê về điểm eHEALS giữa 2 nhóm tần suất tìm kiếm trực tuyến thông tin COVID - 19. Tư kết quả nghiên cứu này, chúng tôi đề xuất những nghiên cứu trong tương lai có thể làm rõ hơn về tác động của thông tin sức khỏe đối với các thay đổi thói quen tìm kiếm để thích ứng với thời kì dịch bệnh.

\section{Tuyên bố về lợi ích xung đột}

Các tác giả tuyên bố không có xung đột lợi ích tiềm ẩn liên quan đến nghiên cứu, quyền tác giả và/hoặc xuất bản bài báo này.

\section{TÀI LIẸU THAM KHẢO}

1. WHO. Coronavirus (COVID - 19) events as they happen. Accessed January 16, 2021. https://www.who.int/emergencies/diseases/ novel - coronavirus - 2019/events - as - they happen

2. Chính phủ nước Cộng hòa xã hội chủ nghĩa Việt Nam. Chính phủ ban hành Nghị quyết về các giải pháp cấp bách phòng, chống dịch bệnh COVID - 19. Accessed August 25, 2021. http://vpcp.chinhphu.vn/Home/Chinh phu - ban - hanh - Nghi - quyet - ve - cac - giai - phap - cap - bach - phong - chong - dich - benh - COVID19/20218/30341.vgp.

3. Google Trends. Search interest for COVID - 19. Google Trends. Accessed December 7, 2020. https://trends.google.com/trends/ explore?q=COVID -19

4. Tasnim S, Hossain MM, Mazumder $\mathrm{H}$. Impact of Rumors and Misinformation on COVID - 19 in Social Media. Journal of Preventive Medicine and Public Health. 2020;53(3):171 -
174. doi:10.3961/jpmph.20.094.

5. DataReportal. Digital 2020: Global Digital Overview. DataReportal. Accessed January 19, 2021. https://datareportal.com/reports/digital 2020 - global - digital - overview.

6. Nguyen TTP, Nguyen DC, Nguyen ATT, et al. Fake News Affecting the Adherence of National Response Measures During the COVID - 19 Lockdown Period: The Experience of Vietnam. Front Public Health. 2020;8:589872. doi:10.3389/fpubh.2020.589872.

7. Bộ Tư pháp. Nghị định 15/2020/NĐ - CP: Chia sẻ thông tin giả mạo, sai sự thật trên mạng xã hội bị phạt đến 20 triệu đồng. Accessed April 9, 2021. https://moj.gov.vn/qt/tintuc/Pages/van - ban - chinh - sach - moi.aspx? ItemID=3103.

8. PhD CP, PhD EH. Health Information Seeking in the Digital Age. Journal of American College Health. 2011;59(5):379 - 386. doi:10.1 080/07448481.2010.513406.

9. Wong DK - K, Cheung M - K. Online Health Information Seeking and eHealth Literacy Among Patients Attending a Primary Care Clinic in Hong Kong: A Cross - Sectional Survey. Journal of Medical Internet Research. 2019;21(3):e10831. doi:10.2196/10831.

10. Norman C, Skinner H. eHEALS: the ehealth literacy scale. Journal of medical Internet research. 2006;8:e27. doi:10.2196/ jmir.8.4.e27.

11. Sharma S, Oli N, Thapa B. Electronic health-literacy skills among nursing students. Adv Med Educ Pract. 2019;10:527 - 532. doi:10.2147/AMEP.S207353.

12. Nguyễn Lan Hoàng, Lê Thị Bích Thủy. E - Health Literacy of Medical Students at a University in Central Vietnam. Indian Journal of Public Health Research \& Development. 2020;11(2):1299 - 1304 - 1304. doi:10.37506/ v11/i2/2020/ijphrd/195001.

13. Dashti S, Peyman N, Tajfard M, Esmaeeli 
H. E - Health literacy of medical and health sciences university students in Mashhad, Iran in 2016: a pilot study. Electron Physician. 2017;9(3):3966 - 3973. doi:10.19082/3966

14. Zhang MW, Tran BX, Le HT, et al. Perceptions of Health - Related Information on Facebook: Cross - Sectional Study Among Vietnamese Youths. Interact $J$ Med Res.
2017;6(2). doi:10.2196/ijmr.8072.

15. Báo Sức khỏe \& Đời sống - Cơ quan ngôn luận của Bộ $Y$ tế. Năng lượng truyền thông trên phòng tuyến chống dịch. Accessed August 27, 2021. https://suckhoedoisong.vn/ nang - luong - truyen - thong - tren - phong tuyen - chong - dich - 169195475.htm.

\section{Summary \\ SEARCHING FOR COVID-19 INFORMATION IN THE INTERNET AMONG FIRST-YEAR STUDENTS OF HANOI MEDICAL UNIVERSITY}

A cross-sectional study was conducted on first-year students of Hanoi Medical University to describe the status of searching for COVID-19 information in the Internet and analyze the differences in eHEALS scores among target groups. Among 346 participants, most people $(94.8 \%)$ used the Internet to search for health information about COVID-19. The total mean score of eHEALS was high $(31.19 \pm 8.34)$. Among the students who searched online for COVID-19 information, smartphone users accounted for the majority (96.65\%), students mainly searched for themselves $(77.46 \%)$ with a frequency of several times a month $(30.49 \%)$. The most searched health content is Disease situation in Vietnam and in the world $(88.72 \%)$. The main reason is to improve knowledge or curiosity $(75.61 \%)$. Social networks $(69.21 \%)$ are the most popular sources of information chosen by the majority of subjects. The main reason for choosing these sources is easy to follow/use $(53.66 \%)$. There was a statistically significant difference in eHEALS scores between the 2 groups of online searching frequency for COVID-19 information.

Keywords: information searching, health information, Internet, COVID-19, eHEALS, medical students 